\title{
Weak-form Efficiency and Causality Tests in Chinese Stock Markets
}

\author{
Martin Laurence \\ William Paterson University of New Jersey, U.S.A. \\ Francis Cai \\ William Paterson University of New Jersey, U.S.A. \\ Sun Qian \\ Nanyang Technological University, Singapore
}

China has two major stock exchanges, the Shanghai and the Shenzen exchanges. Each of these exchanges trades two types of shares, type " $A$ " and type "B" shares. Type "A" shares are available to domestic investors only and type " $\mathrm{B}$ " shares are available to foreign investors. This article tests for the weak-form efficiency in these markets and explores the statistical relationships and causality among these Chinese stock markets with each other and with the U.S. and Hong Kong stock markets. The results indicate the existence of (1) a weak-form efficiency in the market for "A" shares but not "B" shares, (2) statistically weak linkages between the Chinese markets, (3) a weak causal effect from the Hong Kong to the four Chinese markets, and (4) a strong causal effect from U.S. stock mark to all four Chinese stock markets and the Hong Kong Stock market, particularly during the second period of the sample. These results support the assertion that the Chinese stock markets are becoming more integrated to the global economy (JEL G15).

Keywords: Chinese stock markets, Granger causality tests, Hong Kong stock market, market efficiency.

\section{Introduction}

The Shanghai and Shenzen are the two stock exchanges in the People's Republic of China. Shanghai started in 1990 and Shenzen in 1991. The exchanges operate on weekdays 9:30 a.m. to 11:00 a.m. and 1:30 p.m.

(Multinational Finance Journal, 1997, vol. 1, no. 4, pp. 291-307)

(C) by Multinational Finance Society, a nonprofit corporation. All rights reserved. DOI: $10.17578 / 1-4-3$ 
to 3:00 p.m. ${ }^{1}$ Each exchange trades two types of shares, known as type "A" and type "B" shares. Type "A" shares are denominated in Chinese yuan. They are sold to Chinese nationals only. Type "B" shares traded in the Shanghai exchange are denominated in U.S. dollars and those traded in the Shenzen exchange are denominated in Hong Kong dollars. Type "B" shares are sold to investors from Hong Kong, Taiwan, Macau, and other foreign countries. ${ }^{2}$ Both the Shanghai and Shenzen exchanges use computerized trading systems.

The issuance of " $\mathrm{B}$ " shares cannot exceed the limit set by the government, which is $25 \%$ of the total shares of a firm. According to Huang and Liu (1995), "B" shares are intended to attract foreign investments and hard currencies. "B" shares are also developed to limit the investment activities of foreigners so that Chinese stock markets will not be overly influenced by foreign speculators.

By early 1993, the Chinese stock market capitalization had risen to 20 billion U.S. dollars and continued rising to over 100 billion U.S. dollars by 1996. In May 1998, about 789 firms were listed and traded on the Shanghai and Shenzen exchanges. The Chinese government, through the China Securities Regulatory Commission (CSRC), exerts tight control over listings and trading of shares in these exchanges. Although government regulation provides some assurance against fraud and manipulation, it discourages market forces because share listings and sales are by governmental consent, not negotiated with investment banking firms. Interestingly, only " $\mathrm{B}$ " share issuers must adhere to international accounting reporting standards. ${ }^{3}$

Research on the Chinese stock markets is very limited. Only a few articles investigate issues related to the Chinese stock markets. Bailey (1994), using a small sample of firms from the Shanghai and Shenzen exchanges, investigates correlations of weekly returns of " $B$ " shares with returns of international stock indices. He also examines the discount of " $B$ " shares relative to " $A$ " shares. Bailey's data cover the

1. The time difference between New York and Shanghai and Shenzen is 12 hours during summer and 13 hours during winter.

2. Chinese firms can also issue " $\mathrm{H}$ " shares for listing on the Hong Kong stock exchange and "N" shares for listing on the NYSE; e.g., Huang and Liu (1995).

3. A large drop in liquidity of about 25 billion dollars occurred in mid-1994. This was the result of governmental regulations, introduced in 1993, forbidding banks from providing liquidity to market participants. Since then, Chinese authorities reversed these regulations; for additional details, see Spencer (1995), pp. 28-31. 
relatively short period from mid-1992 to the beginning of 1993 . He finds at least partial segmentation of " $B$ " share markets and unexplainable discounts on "B" shares relative to "A" shares. Su and Fleisher (1996) analyze the Chinese stock markets using daily data. They report that the daily and weekly returns of both " $A$ " and " $B$ " shares are non-random. Moreover, they find evidence of cointegration between the " $\mathrm{A}$ "-share markets but not the " $\mathrm{B}$ "-share markets.

The October 1987 international stock market crash and subsequent mini-crashes made it clear that none of the world's markets operates independently. The linkage and causal relationships between international markets are becoming very important to both the private and public sectors in every country. Many U.S. and other international mutual funds and pension funds include Chinese stocks in their portfolios. Knowledge of the linkages between Chinese markets and other foreign markets enables portfolio managers to make more intelligent decisions. Moreover, it helps government officials to maintain stable domestic equity markets and to avoid the potential for international market crises.

This article examines the share-price behavior, weak-form market efficiency, and causality of the Chinese stock markets with each other and with the Hong Kong and U.S. stock markets. The article employs various statistical techniques, such as random walk, and Granger causality tests to investigate the above issues.

The article is organized as follows: Section II discusses the data and presents some preliminary evidence. Section III presents the Granger causality results. Section IV presents the summary and conclusions.

\section{Data and Preliminary Results}

The data include 1,000 daily observations for four Chinese stock market indices and one U.S. and one Hong Kong stock index. The indices used are the Shanghai "A" (SHA), the Shanghai "B" (SHB), the Shenzen "A" (SZA), the Shenzen "B" (SZB), Hong Kong stock exchange index (HK), and the Dow Jones industrial average (DJ) for the U.S. All of these indices are based on closing prices. The data are obtained from Dow Jones News Retrieval Services and Datastream International and cover the period March 8, 1993, to October 31, 1996. Stock index returns are calculated using the continuously compounded formula 
TABLE 1. Unit Root Tests for the Log-Values and Log-Returns of Stock Indices

\begin{tabular}{lcc}
\hline & \multicolumn{2}{c}{ Augmented Dickey Fuller (ADF) Statistics } \\
\cline { 2 - 3 } & \multicolumn{1}{c}{$\begin{array}{l}\text { Levels } \\
\ln \left(P_{t}\right)\end{array}$} & $\begin{array}{c}\text { First Differences } \\
R_{t}=\ln \left(P_{t}\right)-\ln \left(P_{t-1}\right)\end{array}$ \\
\hline SHA & $-2.99^{* *}$ & $-10.07^{*}$ \\
SHB & -1.93 & $-9.01^{*}$ \\
SZA & -.88 & $-8.88^{*}$ \\
SZB & -2.12 & $-8.29^{*}$ \\
HK & 1.01 & $-10.20^{*}$ \\
US & -1.59 & $-9.48^{*}$ \\
\hline
\end{tabular}

Note: SHA is Shanghai "A", SHB is Shanghai "B", SZA is Shenzen "A", SZB is Shenzen "B", HK is Hong Kong Stock market, and US is for the U.S. stock market. $P_{t}$ represent the value of an index at time $t, \ln$ is the natural logarithm, and $R_{t}$ represent the log return series. The ADF statistics test the hypothesis of a unit root in each series. Statistically insignificant statistics imply acceptance of the null hypothesis. *Significant at the $1 \%$ level. **Significant at the $5 \%$ level.

$$
R_{t}=\ln \left(\frac{P_{t}}{P_{t-1}}\right)
$$

where $P_{t}$ is the price of the index at time $t$ and $\ln$ is natural logarithm. Note that $R_{t}=\ln \left(P_{t}-P_{t-1}\right)=\Delta \ln P_{t}$.

To identify possible time structural changes in the behavior of the data, the sample is divided into two sub-samples covering the periods March 8, 1993, to December 31, 1994, and January 1, 1995 to October 31,1996 . Various statistical tests are performed on the two sub-samples as well as the full sample. These include serial correlation tests on daily returns and weekly returns to detect whether these markets exhibit persistent relations over time. Non-normality and runs tests are also used to examine whether the serial correlation tests are influenced by non-normality of the returns.

Before estimating the linkages between different markets, a unit root test is performed for each of the six stock indices using the augmented Dickey-Fuller (ADF) methods; see Dickey and Fuller (1979, 1981). The Dickey-Fuller method involves estimating the model

$$
\Delta Y_{t}=\alpha_{0}+\alpha_{1} t+\alpha_{2} Y_{t-1}+\sum_{s=1}^{k} c_{s} \Delta Y_{t-s}+u_{t}
$$


TABLE 2. Phillips and Ouliaris Residual-based Bivariate Cointegration Tests of the Stock Indices

\begin{tabular}{llcc}
\hline Indices & Period 1 & Period 2 & Periods $1 \& 2$ \\
& $Z_{t}$ & $Z_{t}$ & $Z_{t}$ \\
\hline SHA-SHB & -1.92 & -1.10 & -2.28 \\
SHA-SZA & $-3.43^{*}$ & -2.40 & $-3.55^{*}$ \\
SHA-SZB & -1.93 & -2.52 & -2.62 \\
SHA-US & -2.48 & -1.63 & -2.58 \\
SHB-SZA & -2.01 & -2.73 & -.95 \\
SHB-SZB & -3.23 & -2.19 & -1.98 \\
SHB-US & -2.35 & -2.70 & $-2.77^{* *}$ \\
SZA-SZB & -1.36 & -1.83 & -.79 \\
SZA-US & -2.09 & -.15 & -.66 \\
SZB-US & -1.91 & -1.38 & -1.47 \\
\hline
\end{tabular}

Note: SHA is Shanghai "A", SHB is Shanghai "B", SZA is Shenzen "A", SZB is Shenzen "B", and US is for the U.S. stock market. The critical values for the $Z_{t}$ statistics are -2.76 at the $5 \%$ level and -3.39 at the $1 \%$ level of significance. *Significant at the $1 \%$ level. **Significant at the $5 \%$ level.

where $Y_{t}=\ln \left(P_{t}\right)$ is the natural logarithm of the value of each stock index at time $t, \Delta$ is the first difference operator, and $t$ is for time. Table 1 presents the ADF statistics for testing the null hypothesis of a unit root $\mathrm{H}_{0}: \alpha_{2}=0$ against the alternative hypothesis of a stationary time-series $\mathrm{H}_{1}: \alpha_{2}<0$. All ADF statistics provide support to the null hypothesis of a unit root at the one-percent level of significance. The table also presents the ADF test statistics for the log returns series, $R_{t}$. Note that, in this case, the variable $Y_{t}=R_{t}$. All ADF statistics reject the null hypothesis of a unit root for the log-return series.

Table 2 provides bivariate cointegration tests for each pair of stock indices using the Phillips and Ouliaris (1990) method. ${ }^{4}$ The PhilipsOuliaris method involves estimating via OLS the regression model

$$
Y_{t}=\beta_{0}+\beta_{1} X_{t}+e_{t}
$$

where $Y_{t}$ and $X_{t}$ are the log values of any two stock indices and $e_{t}$ is the regression residual. The series of residuals $e_{t}$ for a cointegrated pair $Y_{t}$ and $X_{t}$ is expected to be stationary. Table 2 presents Philips-Ouliaris $Z_{t}$ statistics for testing the null hypothesis of cointegration (i.e., that the

4. A pair of economic time series is cointegrated if there is a stationary long-run relationship in this pair, although in the short-run both series deviate from each other. 
TABLE 3. Summary Statistics for Shanghai and Shenzen Stock Exchanges

\begin{tabular}{|c|c|c|c|}
\hline Statistics & Period 1 & Period 2 & Periods $1 \& 2$ \\
\hline \multicolumn{4}{|l|}{ SHA Market } \\
\hline Annualized Daily Return & $24.16 \%$ & $-28.87 \%$ & $-5.42 \%$ \\
\hline Standard Deviation & $2.82 \%$ & $4.23 \%$ & $3.61 \%$ \\
\hline Skewness & 1.8235 & 1.4975 & 1.6160 \\
\hline Kurtosis & 25.5473 & 9.6699 & 14.2281 \\
\hline Max. Return & $27.85 \%$ & $30.85 \%$ & $30.85 \%$ \\
\hline Min. Return & $-18.43 \%$ & $-14.60 \%$ & $-18.43 \%$ \\
\hline Observations & 447 & 463 & 910 \\
\hline \multicolumn{4}{|l|}{ SHB Market } \\
\hline Annualized Daily Return & $-16.11 \%$ & $-27.97 \%$ & $-18.79 \%$ \\
\hline Standard Deviation & $1.04 \%$ & $1.93 \%$ & $1.56 \%$ \\
\hline Skewness & 1.2159 & .2619 & .4201 \\
\hline Kurtosis & 5.3796 & 3.8316 & 5.9453 \\
\hline Max. Return & $5.74 \%$ & $9.53 \%$ & $9.53 \%$ \\
\hline Min. Return & $-3.90 \%$ & $-9.54 \%$ & $-9.54 \%$ \\
\hline Observations & 447 & 463 & 910 \\
\hline \multicolumn{4}{|l|}{ SZA Market } \\
\hline Annualized Daily Return & 3.2989 & -.5198 & 1.3823 \\
\hline Standard Deviation & .2295 & .0382 & .1629 \\
\hline Skewness & 1.2355 & 1.4892 & 1.3958 \\
\hline Kurtosis & 20.1756 & 10.1643 & 13.3628 \\
\hline Max. Return & .25968 & .295 & .295 \\
\hline Min. Return & -.19622 & -.14761 & -.1962 \\
\hline Observations & 439 & 456 & 895 \\
\hline \multicolumn{4}{|l|}{ SZB Market } \\
\hline Annualized Daily Return & .0273 & -.421 & -.1539 \\
\hline Standard Deviation & .0387 & .0126 & .0286 \\
\hline Skewness & -.5316 & -.5316 & -.9353 \\
\hline Kurtosis & 6.1211 & 6.1211 & 29.098 \\
\hline Max. Return & .1222 & .0449 & .1222 \\
\hline Min. Return & -.0719 & -.0719 & -.1668 \\
\hline Observations & 437 & 449 & 886 \\
\hline
\end{tabular}

Note: SHA is Shanghai "A", SHB is Shanghai "B", SZA is Shenzen "A", and SZB is Shenzen "B". Period 1 is from 3/8/93 to 12/31/94 and Period 2 is from 1/1/95 to 10/31/96. Data are collected from the Dow Jones News Retrieval Services and Datastream.

residuals are stationary). The $Z_{t}$ statistics reject the hypothesis of cointegration for almost all pairs of stock indices. These results imply that models for testing linkage or causality in the return series do not require the inclusion of an error correction term.

Table 3 presents some summary statistics on the return series of the 
TABLE 4. Serial Correlations and Ljung-Box Statistics of Daily Returns for the Shanghai and Shenzen Stock Exchanges

\begin{tabular}{|c|c|c|c|c|}
\hline & SHA & SHB & SZA & SZB \\
\hline \multicolumn{5}{|c|}{ A. Serial Correlations } \\
\hline \multicolumn{5}{|l|}{ Lags } \\
\hline 1 & -.0258 & .2304 & -.0181 & .0704 \\
\hline 2 & .0856 & .1024 & .0648 & .0670 \\
\hline 3 & -.0086 & .0168 & -.0094 & .0463 \\
\hline 4 & .0163 & .0815 & .0606 & .0968 \\
\hline 5 & .0546 & .0129 & .0237 & .0009 \\
\hline 6 & -.1106 & -.0169 & -.0739 & -.0045 \\
\hline 7 & .0286 & .0324 & .0199 & -.0409 \\
\hline 8 & -.0111 & .0429 & -.0050 & .1114 \\
\hline 9 & .0720 & .0205 & .0587 & .0271 \\
\hline 10 & -.0771 & -.0035 & -.0445 & .0831 \\
\hline 11 & -.0124 & .0347 & .0104 & -.0573 \\
\hline 12 & .0201 & .0607 & .0282 & -.0152 \\
\hline 13 & -.0308 & .0606 & .0063 & .0583 \\
\hline 14 & .0297 & .0882 & .0029 & .0060 \\
\hline 15 & -.0764 & -.0129 & -.0552 & .0103 \\
\hline 16 & .0525 & -.0062 & .0124 & .0336 \\
\hline 17 & .0003 & .0057 & -.0079 & .0396 \\
\hline 18 & .0050 & .0095 & -.0381 & .0390 \\
\hline 19 & -.0217 & -.0409 & .0164 & .1010 \\
\hline 20 & -.0737 & .0074 & -.1176 & -.0031 \\
\hline 21 & .0177 & .0028 & .0505 & .0634 \\
\hline 22 & .0048 & -.0070 & -.0133 & .0147 \\
\hline 23 & -.0202 & .0072 & .0113 & .0460 \\
\hline 24 & -.0037 & .0234 & .0321 & -.0104 \\
\hline \multicolumn{5}{|c|}{ B. Ljung-Box Statistics } \\
\hline Period 1 & $56.22 *$ & $48.16^{*}$ & $36.78 * *$ & $116.31 *$ \\
\hline Period 2 & 22.34 & $66.46^{*}$ & 21.37 & 32.42 \\
\hline Periods $1 \& 2$ & $49.18 *$ & $85.62 *$ & $40.59 * *$ & $65.27 *$ \\
\hline
\end{tabular}

Note: SHA is Shanghai "A", SHB is Shanghai "B", SZA is Shenzen "A", and SZB is Shenzen " $B$ ". Period 1 is from $3 / 8 / 93$ to $12 / 31 / 94$ and Period 2 is from $1 / 1 / 95$ to 10/31/96. The autocorrelation coefficients are for the entire period. Ljung-Box statistics are computed using 24 lags. *Significant at the $1 \%$ level. **Significant at the 5\% level.

four Chinese stock market indices. These preliminary results indicate that, in most cases, the annualized mean daily returns are negative. ${ }^{5}$ This may be attributed to investor uncertainty about future firm

5. Daily returns are annualized using the formula $A R_{t}=250 \times R_{t}$, which assumes 250 trading days per year. 
TABLE 5. Serial Correlations and Ljung-Box Statistics of Weekly Returns for the Shanghai and Shenzen Stock Exchanges

\begin{tabular}{|c|c|c|c|c|}
\hline & SHA & SHB & SZA & SZB \\
\hline \multicolumn{5}{|c|}{ A. Serial Correlations } \\
\hline \multicolumn{5}{|c|}{ Lags } \\
\hline 1 & .0231 & .1525 & .0501 & -.0994 \\
\hline 2 & -.0710 & .0627 & -.0188 & .0948 \\
\hline 3 & .0344 & .0897 & -.0283 & .0905 \\
\hline 4 & -.1035 & -.0122 & -.1106 & .0993 \\
\hline 5 & -.0566 & .0195 & .1185 & .0992 \\
\hline 6 & .0438 & .0658 & .0537 & .0992 \\
\hline 7 & -.0721 & .0883 & -.0396 & .1665 \\
\hline 8 & .0181 & -.0465 & .0448 & -.1595 \\
\hline 9 & -.0911 & .0033 & -.1958 & .1195 \\
\hline 10 & -.0290 & -.1613 & .0189 & .0299 \\
\hline 11 & .0686 & -.1054 & .1234 & .0455 \\
\hline 12 & -.1091 & -.1314 & -.0334 & -.0077 \\
\hline 13 & .0313 & .1552 & .1460 & -.0081 \\
\hline 14 & .1216 & .0481 & .0805 & .0023 \\
\hline 15 & .0145 & -.0798 & .0034 & -.0754 \\
\hline 16 & .0136 & -.1008 & -.0226 & -.0511 \\
\hline 17 & -.0690 & -.1547 & -.0528 & -.0671 \\
\hline 18 & -.0078 & -.0744 & .0651 & -.0683 \\
\hline 19 & -.1103 & -.0401 & -.0277 & -.0541 \\
\hline 20 & -.0486 & .0235 & -.0950 & -.0407 \\
\hline 21 & .0123 & -.0293 & -.0231 & -.0996 \\
\hline 22 & -.0346 & -.0461 & -.0482 & -.1095 \\
\hline 23 & -.0004 & -.1363 & .0477 & -.0933 \\
\hline 24 & .0325 & -.1803 & .1265 & -.0381 \\
\hline \multicolumn{5}{|c|}{ B. Ljung-Box Statistics } \\
\hline Period 1 & 17.87 & $46.01 *$ & 30.82 & $34.87 * *$ \\
\hline Period 2 & 16.41 & 30.77 & 19.64 & $114.12 *$ \\
\hline Periods $1 \& 2$ & 16.61 & 15.27 & 27.98 & 20.03 \\
\hline
\end{tabular}

Note: SHA is Shanghai "A", SHB is Shanghai "B", SZA is Shenzen "A", and SZB is Shenzen "B". Period 1 is from 3/8/93 to $12 / 31 / 94$ and Period 2 is from $1 / 1 / 95$ to 10/31/96. The autocorrelation coefficients are for the entire period. Ljung-Box statistics are computed using 24 lags. *Significant at the $1 \%$ level. **Significant at the $5 \%$ level.

performance and lack of market liquidity stemming from governmental restrictions on banks' participation in securities lending. The standard deviations of annualized daily returns, relative to those for the U.S., are moderate in size. ${ }^{6}$ Unlike the other three markets, stock returns on

6. The average standard deviation of annual returns for firms traded on the OTC during 
Shenzen "B" are negatively skewed and exhibit high kurtosis values.

Tables 4 and 5 report the serial correlations and Ljung and Box (1978) test statistics for 24 lags for daily and weekly returns, respectively. The Ljung-Box statistics are mostly significant at the 5\% level, indicating the presence of significant serial correlation in the daily return series in all four markets. Autocorrelation in securities markets does not necessarily imply market inefficiency; see Leroy (1973) and Levich (1979). However, the relatively large reported values for autocorrelation may indicate a violation of the weak form of market efficiency, since investors may be able to exploit serial correlation for profit making. Except for Shanghai "B", the magnitude of serial correlation in the remaining three markets decreases during the second period, implying that the Chinese markets are moving closer to becoming efficient. As expected, the degree of serial correlations is weaker for weekly returns; see table 5. Most Ljung-box test statistics are statistically insignificant at the $1 \%$. Note that because of transaction cost, low autocorrelation values are harder to exploit for profit making.

Another factor possibly affecting serial correlation is non-normality of the daily returns distribution. Table 6 summarizes runs tests for price changes between 1 to 5 trading days for the full sample and the two subsamples. Of the 60 runs tests ( 20 per sample period), only 5 are nonsignificant in the overall sample period while 7 are non-significant in the early period and 15 in the latter period. This also suggests increasing market efficiency over time. Five of the six one-day returns calculated for the markets of "A" shares have greater actual than expected runs. This implies a negative serial correlation supporting some of the findings in Table 4. However, of a total of more than 30 runs tests on the markets of " $A$ " shares, only 6 have greater actual than expected runs, but only 2 of those are statistically significant. More importantly, all 30 runs for the markets of "B" shares show fewer actual than expected runs. Nineteen of these runs are statistically significant. These results are in line with the positive serial correlations of " $\mathrm{B}$ " shares in table 4.

\section{Granger Causality Tests}

Granger's (1969) causality tests are used to investigate lead-lag relationships among the four Chinese markets and with certain international markets such as those of the U.S. and Hong Kong. Let $Y_{t}$

the period 1960-84 was 22.4\%; see Ibbotson and Brinson (1987), p. 83. 
TABLE 6. Run Tests on Returns for the Shanghai and Shenzen Stock Exchanges

\begin{tabular}{|c|c|c|c|c|c|c|c|c|c|c|c|c|}
\hline \multirow[b]{2}{*}{ Markets } & \multicolumn{4}{|c|}{ Period 1} & \multicolumn{4}{|c|}{ Period 2} & \multicolumn{4}{|c|}{ Periods $1 \& 2$} \\
\hline & $\mathrm{AR}$ & ER & SD & $\mathrm{Z}$ & $\mathrm{AR}$ & ER & SD & $\mathrm{Z}$ & $\mathrm{AR}$ & ER & SD & $\mathrm{Z}$ \\
\hline \multicolumn{13}{|c|}{ One-day return (differencing interval 1) } \\
\hline SHA & 254 & 232.26 & 10.74 & $2.03 * *$ & 234 & 222.42 & 10.48 & 1.10 & 490 & 454.90 & 15.05 & $2.33 * *$ \\
\hline SHB & 197 & 232.50 & 10.75 & $-3.30 *$ & 203 & 222.42 & 10.48 & -1.85 & 396 & 454.97 & 15.05 & $-3.92 *$ \\
\hline SZA & 249 & 230.31 & 10.65 & 1.76 & 216 & 221.63 & 10.48 & -.54 & 457 & 451.14 & 14.95 & .39 \\
\hline SZB & 212 & 232.19 & 10.73 & -1.88 & 198 & 214.09 & 10.16 & -1.58 & 398 & 451.66 & 14.99 & $-3.58 *$ \\
\hline \multicolumn{13}{|c|}{ Two-day return (differencing interval 2) } \\
\hline SHA & 103 & 116.45 & 7.58 & -1.77 & 101 & 110.30 & 7.34 & -1.27 & 203 & 226.81 & 10.60 & $-2.25 * *$ \\
\hline SHB & 96 & 116.32 & 7.57 & $-2.68 *$ & 95 & 109.60 & 7.29 & $-2.00 * *$ & 191 & 225.99 & 10.56 & $-3.31 *$ \\
\hline SZA & 118 & 113.85 & 7.41 & .56 & 93 & 109.84 & 7.34 & $-2.30 * *$ & 195 & 224.64 & 10.52 & $-2.82 *$ \\
\hline SZB & 87 & 116.39 & 7.58 & $-3.88^{*}$ & 88 & 105.63 & 7.08 & $-2.49 * *$ & 173 & 223.63 & 10.50 & $-4.82 *$ \\
\hline \multicolumn{13}{|c|}{ C. Three-day return (differencing interval 3) } \\
\hline SHA & 72 & 76.95 & 6.12 & -.81 & 71 & 75.50 & 6.08 & -.74 & 138 & 152.30 & 8.68 & -1.65 \\
\hline SHB & 70 & 77.24 & 6.14 & -1.18 & 63 & 72.28 & 5.82 & -1.59 & 135 & 150.48 & 8.57 & -1.81 \\
\hline SZA & 65 & 75.12 & 5.97 & -1.69 & 60 & 73.52 & 5.96 & $-2.27 * *$ & 132 & 149.47 & 8.54 & $-2.04 * *$ \\
\hline SZB & 61 & 77.24 & 6.14 & $-2.64 *$ & 64 & 73.41 & 5.99 & -1.57 & 116 & 150.48 & 8.63 & $-4.00 *$ \\
\hline
\end{tabular}


TABLE 6. (Continued)

D. Four-day return (differencing interval 4)

\begin{tabular}{|c|c|c|c|c|c|c|c|c|c|c|c|c|}
\hline SHA & 5 & 57.24 & 5.22 & -.43 & 53 & 56.28 & 5.22 & -.63 & 101 & 113.70 & 7.46 & -1.70 \\
\hline SHB & 46 & 57.77 & 5.27 & $-2.23 * *$ & 53 & 54.87 & 5.09 & -.37 & 99 & 112.38 & 7.38 & -1.81 \\
\hline SZA & 58 & 57.97 & 5.29 & .00 & 48 & 53.84 & 5.04 & -1.16 & 108 & 113.12 & 7.46 & -.69 \\
\hline SZB & 40 & 58.46 & 5.33 & $-3.46^{*}$ & 46 & 52.81 & 4.98 & -1.37 & 80 & 111.51 & 7.38 & $-4.27 *$ \\
\hline \multicolumn{13}{|c|}{ E. Five-day return (differencing interval 5) } \\
\hline SHA & 42 & 46.05 & 4.70 & -.86 & 40 & 44.22 & 4.61 & -.92 & 80 & 89.87 & 6.62 & -1.49 \\
\hline SHB & 38 & 45.84 & 4.67 & -1.68 & 37 & 41.97 & 4.36 & -1.14 & 79 & 88.46 & 6.52 & -1.45 \\
\hline SZA & 47 & 46.23 & 4.71 & .16 & 36 & 42.43 & 4.41 & -1.46 & 86 & 89.27 & 6.58 & -.50 \\
\hline SZB & 27 & 46.45 & 4.74 & $-4.11 *$ & 32 & 43.49 & 4.58 & $-2.51 * *$ & 58 & 89.47 & 6.63 & $-4.75^{*}$ \\
\hline
\end{tabular}

Note: SHA is Shanghai "A", SHB is Shanghai "B", SZA is Shenzen "A", and SZB is Shenzen "B". AR is the total number of runs, ER is the expected runs, SD is the standard deviation of runs, $\mathrm{Z}=($ Return $-\mathrm{ER}) / \mathrm{SD},$. *Statistically significant at the $1 \%$ level. **Statistically significant at the $5 \%$ level. 
and $X_{t}$ be the return series for two different markets. The following standard definition for Granger's causality is used:

Returns in market " $X$ " cause returns in market " $Y$ " if and only if the past values of $X_{t}$ combined with past values of $X_{t}$ improve the prediction of $Y_{t}$.

The empirical procedure for testing Granger's causality from market $X$ to markets $Y$ involves the following steps. Estimate an autoregressive $(A R)$ model of order $p$

$$
Y_{t}=\alpha_{0}+\alpha_{1} Y_{t-1}+\cdots+\alpha_{p} Y_{t-p}+e_{t}
$$

where $Y_{t}$ represents the return in market " $Y$ " at time $t$. The lag-length $p$ of (4) is determined using Akaike's minimum final prediction error (FPE). According to the FPE criterion, the optimal value of $p$ is the one that minimizes the FPE statistic; see Hsiao (1981) for the details.

Next, estimate an expanded version of equation 4 which includes past values of the $X_{t}$ series. That is, estimate

$$
\begin{aligned}
Y_{t}= & \alpha_{0}+\alpha_{1} Y_{t-1}+\cdots+\alpha_{k} Y_{t-p} \\
& +\beta_{1} X_{t-1}+\cdots+\beta_{k} X_{t-q}+u_{t} .
\end{aligned}
$$

The lag-length of $X_{t}$ is also determined using the FPE criterion, given the value of $p$ from the estimation of equation 4 .

The F-statistic below

$$
F=\frac{\left(S S R_{1}-S S R_{2}\right) / q}{S S R_{2} /(T-p-q-1)}
$$

where $S S R_{1}$ is the sum of squared residuals of (4), $S S R_{2}$ is the sum of squared residuals of (5), $T$ is the sample size, and $p$ and $q$ are as defined previously, provides a formal test for causality. Specifically, a statistically significant value indicates causality from market " $X$ " to market ' $Y$ '.

Table 7 presents the optimal values for $p$ and $q$ and F-values for testing bivariate causality between all possible pairs of the Chinese stock markets. It also presents similar statistics for possible bivariate 
causality from the U.S. and Hong Kong stock markets to all four Chinese markets.

Panel A presents the statistics for bivariate causality among the four Chinese markets. The results show that Shanghai " $A$ " has no apparent influence on Shenzen "A". All F-values are statistically insignificant. A causal relation exists from Shanghai "A" to Shanghai "B" in the second period and from Shanghai "A" to Shenzen "B" in the first period. Shenzen "A" appears to lead Shanghai "A" during the first period, but not in the second period, suggesting a fading leadership over time. This may be attributed to the late paramount leader Deng's efforts to establish Shenzen as the "pilot" or model center of economic development and reform for China. Shanghai "B" influences the other three markets during both periods. Shenzen "B" influences Shanghai "A" and Shenzen "A" during the first period and Shanghai "B" during the second period, only. In sum, these results suggest a causal relationship from Shanghai " $B$ " to all Chinese markets and from Shanghai "A" and Shenzen "B" back to Shanghai "B". The causal relationships from the " $B$ " markets to the "A" imply that foreign markets exert a significant influence on the markets open only to Chinese nationals. ${ }^{7}$

Panel B of table 7 presents the statistics for testing causality from the Hong Kong stock market to the four Chinese markets. The results indicate a strong causal relation from the HK market to Shanghai "B" during the first period and to Shanghai "A" during the second period, only. No causal relation exists between the HK market with Shenzen "A" or Shenzen "B". The latter result may be attributed to the proximity of Shenzen to Hong Kong, which may have made it a de facto Chinese market.

Panel C of table 7 demonstrates that the U.S. stock market exhibit a strong causal relation to all four Chinese markets as well as the Hong Kong market during the second period. These relations are, however, weak for Shanghai "B", Shenzen "A", and Shenzen "B" during the first period. This suggests that the four Chinese markets are gradually being integrated into global financial markets.

The following explanation could be offered regarding the gradual integration of Chinese markets into the world markets. There is an increasing interest of international investors towards the Chinese markets. For example, there were no U.S. mutual funds investing in

7. It is important to note that shares are not cross-listed in the four Chinese markets. 
TABLE 7. Bivariate Causality Tests Among the Four Chinese Stock Markets and from the Hong Kong and the U.S. Stock Markets to the Chinese Stock Markets

\begin{tabular}{|c|c|c|c|c|c|c|c|c|c|}
\hline & \multicolumn{3}{|c|}{ Period 1} & \multicolumn{3}{|c|}{ Period 2} & \multicolumn{3}{|c|}{ Periods $1 \& 2$} \\
\hline \multicolumn{10}{|c|}{$\begin{array}{l}\text { A. Causality Among } \\
\text { the Chinese Markets }\end{array}$} \\
\hline SHA to SHB & 8 & 1 & .48 & 7 & 9 & $2.49 * *$ & 8 & 6 & 1.81 \\
\hline SHA to SZA & 7 & 1 & .54 & 3 & 1 & .06 & 6 & 1 & .32 \\
\hline SHA to SZB & 8 & 4 & $4.30 *$ & 3 & 1 & 1.92 & 2 & 7 & $3.87^{*}$ \\
\hline $\mathrm{SHB}$ to $\mathrm{SZA}$ & 7 & 1 & $3.11 *$ & 3 & 4 & $2.01 * *$ & 6 & 2 & $3.57 *$ \\
\hline SHB to SZB & 8 & 7 & $9.71 *$ & 3 & 8 & $2.50 * *$ & 2 & 8 & $4.66^{*}$ \\
\hline SZA to SHA & 9 & 2 & $9.45 * *$ & 3 & 1 & .30 & 9 & 5 & $4.57 * *$ \\
\hline SZA to SHB & 8 & 1 & $2.98 * *$ & 7 & 1 & .18 & 8 & 5 & $2.36^{* *}$ \\
\hline SZA to SZB & 8 & 3 & $7.82 * *$ & 3 & 1 & 3.94 & 2 & 7 & $4.36 * *$ \\
\hline
\end{tabular}


TABLE 7. (Continued)

\begin{tabular}{|c|c|c|c|c|c|c|c|c|c|}
\hline & \multicolumn{3}{|c|}{ Period 1} & \multicolumn{3}{|c|}{ Period 2} & \multicolumn{3}{|c|}{ Periods $1 \& 2$} \\
\hline & $\bar{p}$ & $q$ & F-value & $\bar{p}$ & $q$ & F-value & $\bar{p}$ & $q$ & F-value \\
\hline \multicolumn{10}{|c|}{$\begin{array}{l}\text { B. Causality from HK to } \\
\text { the Chinese Markets }\end{array}$} \\
\hline HK to SHA & 9 & 3 & 1.40 & 3 & 6 & $2.10 * *$ & 9 & 6 & $2.46^{* *}$ \\
\hline HK to SHB & 8 & 5 & $6.39 *$ & 7 & 1 & .02 & 8 & 5 & $7.49 *$ \\
\hline HK to SZA & 7 & 1 & .05 & 3 & 1 & .07 & 6 & 1 & .04 \\
\hline HK to SZB & 8 & 4 & 1.56 & 3 & 1 & 1.34 & 2 & 1 & .34 \\
\hline
\end{tabular}

to the Chinese markets

\begin{tabular}{lllllllll} 
US to SHA & 9 & 1 & $2.13 * *$ & 3 & 2 & $2.71 * *$ & 9 & 4 \\
US to SHB & 8 & 1 & 1.02 & 7 & 1 & $2.99 * *$ & 8 & 1.52 \\
US to SZA & 7 & 2 & 1.50 & 3 & 1 & $2.55^{* *}$ & 6 & 1 \\
US to SZB & 8 & 1 & .20 & 3 & 1 & $2.23 * *$ & 2 & 1 \\
US to HKS & 7 & 2 & $31.19 *$ & 8 & 1 & $25.0^{*}$ & 74 & 7.46 \\
\hline
\end{tabular}

Note: SHA is Shanghai "A", SHB is Shanghai "B", SZA is Shenzen "A", SZB is Shenzen "B", HK is Hong Kong Stock Exchange, and US is for the U.S. stock market. Period 1 is from 3/8/93 to 12/31/94 and Period 2 is from 1/1/95 to 10/31/96. *Significant at the $1 \%$ level. **Significant at the $5 \%$ level. 
Chinese companies before 1993. By the end of 1997, there were many U.S. mutual funds companies that invested in China. Moreover, an increasing number of Chinese companies are now dually listed in U.S. markets. Therefore, Chinese markets get feedback of the movements from these dual listing stocks.

\section{Summary and Conclusions}

This article tests for the weak-form efficiency in the four Chinese stock markets of Shanghai "A", Shanghai "B", Shenzen "A", and Shenzen "B" and explores the presence of causality influences between these markets as well as the U.S. and Hong Kong stock markets.

The Ljung-Box test statistics indicate the presence of significant serial correlation in the daily return series in all four Chinese markets. This may be interpreted as a violation of the weak form of market efficiency, since investors may be able to exploit serial correlation for profit making. Except for Shanghai "B", the magnitude of serial correlation in the remaining three markets decreases during the second period of the data, implying that the Chinese markets are moving closer to becoming efficient.

Granger causality tests indicate a causal relationship from Shanghai "B" to the other three Chinese stock markets and from Shanghai "A" and Shenzen "B" back to Shanghai "B". The causal relationships from the "B" stock markets to the "A" stock markets imply that foreign markets exert a significant influence on the markets open only to Chinese nationals. The Hong Kong stock market exerts a significant causal relationship on Shanghai "B" during the first period and on Shanghai "A" during the second period. The U.S. stock market exhibits a strong causal relation to all four Chinese markets as well as the Hong Kong market, especially during second period. These results suggests that the four Chinese markets are gradually being integrated into the global economy.

\section{References}

Bailey, W. 1994. Risk and return on China's new stock markets: Some preliminary evidence. Pacific-Basin Finance Journal 2: 243-260.

Dickey, D. A., and Fuller, W. A. June 1979. Distribution of the estimates for 
autoregressive time series with unit root. Journal of the American Statistical Association 74: 427-32.

Dickey, D. A. and Fuller, W. A. July 1981. Likelihood ratio statistics for autoregressive time series with a unit root. Econometrica 49: 1057-72.

Granger, C. W. J. 1969. Investigating causal relations by econometric models and cross-spectral methods. Econometrica 37(3): 424-437.

Hsiao, C. 1981, Autoregressive modeling and money-income causality detection, Journal of Monetary Economics 7: 85-106.

Huang, M., and Liu, Z. 1995. Encyclopedia of stock markets. Chongqin: Chongqin Publishing.

Ibbotson, R. G., and Brinson, G. P. 1987. Investment markets: Gaining the performance advantage. New York: McGraw-Hill Book Company.

Leroy, S. F. 1973. Risk aversion and the Martingale property of stock returns. International Economic Review 14: 436-446.

Levich, R. M. 1979. On efficiency of markets for foreign exchange, in R. Dornbusch and J. Frenkel (eds), International Economic Policy. Baltimore, MD: Johns Hopkins University Press.

Ljung, G. M., and Box, G. E. P., 1978. On a measure of lack of fit in time series. Biometrika 65: 297-303.

Phillips, P. C., and Ouliaris, S. 1990. Asymptotic properties of residual based tests for cointegration. Econometrica 58: 165-193.

Spencer, M. 1995. Securities markets in China. Finance \& Development 32(2): 28-31.

Su, D., and Fleisher, B. M. 1997. Risk, return and regulation in Chinese stock markets. Working paper. 